\title{
Immunologic and Biochemical Factors of Coincident Celiac Disease and Type 1 Diabetes Mellitus in Children
}

\author{
MAŁGORZATA MYŚLIWIEC, ANNA BALCERSKA, KATARZYNA ZORENA, JOLANTA MYŚLIWSKA, \\ AND PIOTR WIŚNIEWSKI
}

\author{
Departments of Pediatrics, Hematology, Oncology and Endocrinology [M.M., A.B.], Department of Immunology [K.Z., J.M.], Departments \\ of Internal Medicine, Endocrinology and Haemostatic Disorders [P.W.] Medical University of Gdańsk, 80-952 Gdańsk, Poland
}

\begin{abstract}
The objective of the study was to investigate whether immunologic and biochemical events occurring in the course of type 1 diabetes mellitus might play a role in the development of the celiac disease. The study was carried out on 223 children with longstanding diabetes mellitus type 1 (DM1). All the patients had TSH, fT4, fT3, urinary albumin secretion rate, IgA, level of antigliadin antibodies (AGA) IgA and $\mathrm{IgG}$, antitissue transglutaminase IgA antibodies, antiendomysium (EmA) IgA and IgG antibodies and antitireoglobulin antibodies, antithyroid peroxidase antibodies evaluated. Serum TNF- $\alpha$, IL-6, and IL-10 levels were also measured. The group of children with coincident DM1 and celiac disease and without autoimmune thyroiditis was characterized by significantly higher glycosylated hemoglobin, higher serum TNF- $\alpha$, IL-6 but lower serum IL-10 in relation to the remaining diabetic patients. A statistically significant positive correlation was observed between IgA-anti-tTG and serum TNF- $\alpha(R=0.28, p=0.026)$; between IgG AGA and serum IL-6 $(R=0.31, p=0.023)$; and between glycosylated hemoglobin and IgA-anti-tTG $(R=0.21, p=0.001)$ and $\operatorname{IgA}$ antiendomysium $(R=0.22, p=0.001)$. Poor metabolic control, persistent elevated levels of proinflammatory cytokines, and decreased level of antiinflammatory cytokines occurring in the course of type 1 diabetes mellitus might influence the incidence of celiac disease. (Pediatr Res 64: 677-681, 2008)
\end{abstract}

$\mathrm{V}$ arious publications report correlation between diabetes mellitus type 1 (DM1) and incidence of other autoimmune disorders, particularly thyroid and celiac diseases (1). According to various data, 1.0-10.4\% of children diagnosed with DM1 develop celiac disease - the data vary according to age and diagnostic methods (2). In Northern Poland, celiac disease was present in $5.7 \%$ of children at the onset of DM1. Conversely, $9.4 \%$ of children with long-standing DM1 had concomitant celiac disease (3). Although numerous works regarding the coincidence of DM1 and celiac disease were published in recent years, the ethiopathogenesis of celiac disease development in diabetic patients is not fully understood. One argument in favor of common inclination is the fact that the same alleles of the genes HLA-DQA1 and DQB1 predispose for development of both celiac disease and DM1 $(4,5)$. However, the association of the two autoimmune diseases with the same HLA region only partially provides

Received February 11, 2008; accepted July 16, 2008.

Correspondence: Małgorzata Myśliwiec, M.D, Ph.D., Diabetology Unit, Department of Pediatrics, Hematology, Oncology and Endocrinology, Medical University of Gdańsk, ul. Dębinki 7, 80-952 Gdańsk, Poland; e-mail: mysliwiec@amg.gda.pl

Supported by the Medical University of Gdańsk (grants: ST 8 to A.B., ST 28 to J.M.). evidence for the existence of genetic predisposition and the similarities in the pathogenesis of the auto-aggression reactions, especially in the patients, who do not have the HLADQA $1 * 0501$ and DQB $1 * 0201$ heterodimer.

The question arises, whether the disturbances of the equilibrium between subpopulations of helper lymphocytes: $\mathrm{T}_{\mathrm{H}} 1$ and $\mathrm{T}_{\mathrm{H}} 2$ as observed in children with DM1 might lead toward development of celiac disease in this particular group of patients (6). Our previous studies have shown that TNF- $\alpha$ and IL-6 play crucial role in the mechanisms of damage to the eye apparatus and kidneys of the diabetic patients (7-10). It remains unresolved to what extent changes in the levels of pro- and antiinflammatory cytokines that occur in the course of DM1 might affect occurrence of celiac disease in such patients.

This work aimed to assess the correlation between the levels of TNF- $\alpha$, IL-6, IL-10 and celiac disease development in children diagnosed with DM1.

\section{MATERIALS AND METHODS}

The study was conducted on a group of 223 children with long-standing DM1 (105 boys, 118 girls) aged $12.20 \pm 3.87 \mathrm{y}$; the duration of the disease being $4.47 \pm 3.16 \mathrm{y}$. All of the children were patients of the Outpatient Diabetology Clinics and the Department of Pediatrics, Hematology, Oncology and Endocrinology at the Medical University of Gdańsk, Poland. The diagnosis of DM1 was made in accordance with the American Diabetes Association Criteria (11).

All the patients were treated using humanized insulin. In children with long-standing DM1, the average daily insulin dose was $0.93 \pm 0.35$ unit $/ \mathrm{kg}$. The disease metabolic compliance was assessed based on the level of glycosylated $\mathrm{Hb}(\mathrm{HbA} 1 \mathrm{c})$ measured in the blood by immunoturbidimetric method using a Unimate 3 set (Hoffmann-La Roche AG, Germany). C-reactive protein level was measured using a highly sensitive test (HsCRP).

Every patient, while being hospitalized in the Department in the years 2003-2005, was subject to all of the celiac disease screening tests. These included detection of antigliadin antibodies in both $\operatorname{IgA}$ and $\operatorname{IgG}$ classes (IgA-AGA/IgG-AGA), antitissue transglutaminase IgA antibodies (IgA-antitTG), and antiendomysium $\operatorname{IgA}$ and $\operatorname{IgG}$ antibodies (IgA-EmA/IgG-EmA). Additionally, the total level of IgA was measured to exclude cases of IgA deficiency. Final diagnosis of celiac disease depended on the results of jejunal biopsy, in accordance with criteria set by European Society for Pediatric Gastroenterology and Nutrition $(12,13)$.

Biopsy samples were obtained through an endoscopy procedure using an Olympus gastroscope (Tokyo, Japan) with four to five specimens being taken from the second portion of the duodenum. All biopsy specimens were blindly

Abbreviations: AGA, antigliadin antibodies; CV, mean variability coefficient; DM1, diabetes mellitus type 1; EmA, antiendomysium antibodies; HbA1c, glycosylated hemoglobin; TG, tyreoglobulin; TPO, thyroid peroxidase; tTG, tissue transglutaminase 
evaluated by a pathologist and a gastroenterologist and classified according to Marsh classification.

To detect thyroid disorders, all the patients were evaluated with regard to hormone studies (TSH, fT4, fT3), levels of antitireoglobulin (anti-TG) and antithyroid peroxidase (anti-TPO) antibodies, and results of thyroid ultrasound examination.

The EmA antibodies were measured by means of indirect immunofluorescent method that was performed on cryostat fragments of the human umbilical cord tissue. The first layer consisted of serum from the examined case, whereas the second contained rabbit immunoserum, labeled with FITC, directed against human EmA class $\operatorname{IgA}$ and class $\operatorname{IgG}$ (purchased form DAKO, Glostrup, DK). The cases, in which for the first layer PBS or a known EmA positive serum was used, were used as controls. The results were analyzed by fluorescent microscopy. Titers lower than 1:10 were judged to be the negative threshold. IgA-anti-tTG, IgA-AGA/IgG-AGA, anti-TG, antiTPO antibodies were detected by means of an immunoenzymatic method (ELISA). ELISA tests were performed using commercial kits purchased from Hycor Biomedical, Inc., San Diego, CA, and Orgentec Diagnostics, Germany. The final result of the patient was calculated as mean value of two measurements. The reference values for examined antibodies were IgA-anti-tTG $<7$ $\mathrm{U} / \mathrm{mL}$ [mean variability coefficient $(\mathrm{CV})$ for analyzed cases and controls $-3.08 \%$ ], IgA-AGA $<12 \mathrm{U} / \mathrm{mL}(\mathrm{CV}-5.0 \%)$, IgG-AGA $<12 \mathrm{U} / \mathrm{mL}(\mathrm{CV}$ $-4.4 \%)$, anti-TG $<100 \mathrm{IU} / \mathrm{mL}(\mathrm{CV}-1.45 \%)$, anti-TPO $<50 \mathrm{IU} / \mathrm{mL}(\mathrm{CV}$ $-2.57 \%)$.

Additionally, all the examined children had TNF- $\alpha$, IL-6, and IL-10 serum levels measured using immunoenzymatic ELISA method (Quantikine High Sensitivity Human by R\&D Systems, Minneapolis, MN) according to the manufacturer's protocol. Minimum detectable concentrations were determined by the manufacturer as $0.12 \mathrm{pg} / \mathrm{mL}, 0.03 \mathrm{pg} / \mathrm{mL}$, and $1.0 \mathrm{pg} / \mathrm{mL}$, respectively. Intraassay (2.6 for $\mathrm{TNF}-\alpha ; 1.6$ for IL-6; 1.7 for IL-10) and interassay (7.4 for TNF- $\alpha$; 6.4 for IL-6; 7.5 for IL-10) precision's performances of the assays were determined on 20 replicates from the quality control data of the laboratory.

Blood collection. Blood samples were collected from 7 to 9 o'clock after an overnight fast. The sera were separated from the venous blood within 30 min and kept frozen at $-80^{\circ} \mathrm{C}$ up to 3 mo before analysis. All measurements were done on the same blood sample.

Patients with long-standing DM1 were subdivided into two groups: children with DM1 and celiac disease but without autoimmune thyroiditis and without microalbuminuria (group $\mathrm{A} ; n=19$ ) and children with DM1 but without celiac disease, autoimmune thyroiditis, and microalbuminuria (group $\mathrm{B} ; n=160$ ). Group B was regarded as a control group. The DM1 patients, who on the basis of clinical, biochemical, laboratory, hormonal, and immunologic studies were diagnosed with urinary, liver, respiratory disease, or any disorder of autoimmune origin other then DM1 were excluded from group A and $\mathrm{B}$.

Parents of all of the children in the study gave informed consent. In addition, positive recommendation from Independent Bioethical Committee for Scientific Research at Medical University of Gdańsk (NKEBN/610/2003/ 2004) was obtained.

Statistical analysis. The results were analyzed using Statistica 7.0 program (StatSoft, Pl). The Kolmogorov-Smirnov test was used to evaluate normality of variables. Logarithmic transformation was applied to variables as required. The differences between the groups were calculated with $t$ test or the nonparametric Mann-Whitney U tests. The Spearman or the Pearson correlations were examined. In this study, a value of $p<0.05$ was considered statistically significant.

\section{RESULTS}

Twenty-one (9.4\%) of 223 examined DM1 patients were diagnosed to have celiac disease based on positive result of jejunal biopsy. Additionally, 44 (19.7\%) patients were diagnosed with autoimmune thyroiditis.

Children with long-standing DM1 and diagnosed celiac disease (group A) were significantly older at diagnosis of DM1 $(p=0.003)$, and were characterized by significantly higher level of HbA1c $(<0.001)$, CRP $(<0.001)$, and $24 \mathrm{~h}$ urinary albumin secretion $(p=0.013)$. No statistically significant differences between the two groups in thyroid hormone levels and BMI were observed (Table 1).

Significantly higher mean level of IgA-AGA $(p<0.001)$, IgG-AGA $(p<0.001)$, IgA-EmA $(p<0.001)$, IgG-EmA
Table 1. Clinical and biochemical parameters of children with diabetes mellitus type 1 and celiac disease (group A) and children with diabetes mellitus type 1 and no concurrent celiac disease (group B)

\begin{tabular}{lccc}
\hline \multicolumn{1}{c}{ Parameters } & Group A $(n=19)$ & Group B $(n=160)$ & $p$ \\
\hline Age $(\mathrm{y})$ & $11.15 \pm 4.34$ & $11.06 \pm 4.25$ & 0.870 \\
Sex $(\mathrm{F} / \mathrm{M})$ & $15 / 4$ & $83 / 77$ & 0.053 \\
Duration of & $3.24 \pm 3.11$ & $6.10 \pm 3.22$ & $0.021^{*}$ \\
$\quad$ diabetes (y) & & & \\
BMI $\left(\mathrm{kg} / \mathrm{m}^{2}\right)$ & $18.63 \pm 3.30$ & $18.00 \pm 3.11$ & 0.338 \\
Dose insulin & $0.89 \pm 0.31$ & $0.92 \pm 0.28$ & 0.451 \\
$\quad($ unit/kg/24 h) & & & \\
C-peptide-serum & $<0.05$ & $<0.05$ & - \\
$\quad(\mathrm{ng} / \mathrm{mL})$ & & & \\
HbA1c-serum $(\%)$ & $9.49 \pm 2.13$ & $8.26 \pm 1.97$ & $0.001^{*}$ \\
Albumin excretion & $12.8 \pm 11.6$ & $6.20 \pm 5.80$ & $0.013^{*}$ \\
$\quad$ rate $(\mathrm{mg} / 24 \mathrm{~h})$ & & & \\
CRP-serum $(\mathrm{mg} / \mathrm{L})$ & $3.36 \pm 1.47$ & $1.08 \pm 0.82$ & $0.001^{*}$ \\
TSH $(\mu \mathrm{U} / \mathrm{mL})$ & $2.02 \pm 0.62$ & $1.93 \pm 0.99$ & 0.843 \\
FT4 (pmol/L) & $15.02 \pm 2.41$ & $14.57 \pm 2.50$ & 0.805 \\
FT3 (pmol/L) & $3.83 \pm 0.92$ & $5.53 \pm 0.22$ & 0.818 \\
\hline
\end{tabular}

* Statistical significance $(p<0.05)$.

Table 2. Immunologic parameters of children with diabetes mellitus type 1 and celiac disease (group A) and children with diabetes mellitus type 1 and no concurrent celiac disease and autoimmune thyroiditis (group B)

\begin{tabular}{|c|c|c|c|}
\hline $\begin{array}{l}\text { Immunological } \\
\text { parameters }\end{array}$ & Group A $(n=19)$ & Group B $(n=160)$ & $p$ \\
\hline $\begin{array}{l}\text { IgA-anti-tTG } \\
(\mathrm{U} / \mathrm{mL})\end{array}$ & $85.37(0.63-239.95)$ & $3.40(0.00-28.02)$ & $<0.001^{*}$ \\
\hline $\operatorname{IgA}$ AGA $(\mathrm{U} / \mathrm{mL})$ & $51.01(0.63-258.70)$ & $3.30(0.00-40.00)$ & $<0.001 *$ \\
\hline $\operatorname{IgG}$ AGA $(\mathrm{U} / \mathrm{mL})$ & $34.94(1.10-170.50)$ & $5.73(0.005-42.50)$ & $<0.001 *$ \\
\hline $\begin{array}{l}\text { IgA EmA-positive } \\
\text { patients }(n)\end{array}$ & $11 / 19$ & $0 / 160$ & $<0.001 *$ \\
\hline $\begin{array}{l}\text { IgG EmA-positive } \\
\text { patients }(n)\end{array}$ & $3 / 19$ & $0 / 160$ & $<0.001^{*}$ \\
\hline $\operatorname{Ig} \mathrm{A}(\mathrm{g} / \mathrm{L})$ & $2.16(2.08-2.63)$ & $2.12(1.98-2.58)$ & 0.323 \\
\hline $\begin{array}{l}\text { Serum } \\
\text { TNF- } \alpha(\mathrm{pg} / \mathrm{mL})\end{array}$ & $2.65(1.10-4.75)$ & $0.41(0.00-1.80)$ & $<0.001^{*}$ \\
\hline $\begin{array}{l}\text { Serum } \\
\quad \text { IL-6 }(\mathrm{pg} / \mathrm{mL})\end{array}$ & $2.36(0.35-4.36)$ & $0.50(0.00-2.13)$ & $<0.001^{*}$ \\
\hline $\begin{array}{l}\text { Serum } \\
\quad \text { IL-10 }(\mathrm{pg} / \mathrm{mL})\end{array}$ & $0.73(0.00-3.47)$ & $1.69(0.00-4.70)$ & $0.03 *$ \\
\hline
\end{tabular}

* Statistical significance $(p<0.05)$.

( $p<0.001)$, IgA-anti-tTG $(p<0.001)$ antibodies as well as TNF- $\alpha$ and IL-6 serum values $(p<0.001 ; p<0.001)$ were found in group A in relation to group B. However, serum IL-10 in the group A was significantly lower then in the group B (Table 2).

The group of children with DM1 and celiac disease ( $n=19$, duration of diabetes: $3.24 \pm 3.11 \mathrm{y}$ ) when compared with the group of diabetic patients without celiac disease but of similar duration of the disease ( $n=129$, duration of diabetes: $3.41 \pm$ $2.98 \mathrm{y})$ had statistically significant differences in the cytokine levels. TNF- $\alpha(p<0.001)$ and IL-6 $(p<0.001)$ were significantly higher whereas IL-10 $(p=0.02)$ was significantly lower in the group of diabetic patients diagnosed to have concomitant celiac disease.

In all the examined children with DM1, the C-peptide level was found to be less than $0.5 \mathrm{ng} / \mathrm{mL}$. 
Table 3. Correlation between biochemical and immunological parameters in children with diabetes mellitus type 1

\begin{tabular}{llc}
\hline $\begin{array}{c}\text { Biochemical and immunological } \\
\text { parameters }\end{array}$ & $R$ & $p$ \\
\hline HbA1c vs IgA-anti-EmA & 0.22 & 0.001 \\
HbA1c vs IgA-anti-tTG & 0.21 & 0.001 \\
CRP vs IgA-anti-EmA & 0.26 & 0.000 \\
CRP vs IgG-anti-EmA & 0.22 & 0.014 \\
CRP vs IgA-anti-tTG & 0.16 & 0.016 \\
TNF vs IgA-anti-tTG & 0.28 & 0.026 \\
IL-6 vs IgA AGA & 0.31 & 0.023 \\
IL-10 vs IgA-anti-tTG & -0.27 & 0.015 \\
\hline
\end{tabular}

Table 4. Sensitivity and specificity of serologic test for celiac disease detection in DM1 children

\begin{tabular}{lcc}
\hline Serologic test & Sensitivity $(\%)$ & Specificity $(\%)$ \\
\hline IgA anti-tTG & 95.2 & 95.0 \\
IgA AGA & 76.2 & 84.1 \\
IgG AGA & 80.4 & 88.3 \\
IgA EmA & 61.9 & 100.0 \\
IgG EmA & 68.5 & 78.2 \\
\hline
\end{tabular}

\section{Correlation between biochemical and immunologic} parameters in children with DM1. There was a statistically significant positive correlation between CRP levels and IgAanti-tTG $(R=0.16, p=0.016)$ and both classes of EmA antibodies: $\operatorname{IgA}(R=0.26, p=0.000)$ and $\operatorname{IgG}(R=0.17, p=$ $0.014)$ observed in children with DM1. Additionally, significant positive correlation between $\mathrm{HbA} 1 \mathrm{c}$ and $\mathrm{IgA}$-anti-tTG $(R=0.21, p=0.001)$ and $\operatorname{IgA} \operatorname{EmA}(R=0.22, p=0.001)$ was found. There was also a statistically significant positive correlation between IgA-anti-tTG and serum TNF- $\alpha(R=$ $0.28, p=0.026)$ and IgG AGA and serum IL-6 $(R=0.31$, $p=0.023)$. Finally, significant negative correlation between IgA-anti-tTG and serum IL-10 $(R=-0.27, p=0.015)$ was observed (Table 3).

Sensitivity assessment of the tests for celiac disease diagnosis in DM1 children. The highest sensitivity (95.2\%) of celiac disease detection in DM1 children was found in the case of serologic test detecting anti-tTG (IgA tTG), whereas the lowest sensitivity characterized test aimed at antiednomysium antibody (IgA EmA) detection (61.9\%). However, the specificity of both tests was comparable-(IgA tTG-95\%, IgA EmA-100\%) (Table 4).

\section{DISCUSSION}

The pathomechanism of the celiac disease development in DM1 children remains, for the most part, unknown. Published studies do not give a clear answer whether immunologic disorders observed in DM1 children with concomitant celiac disease are of primary character and thus directly related to the ethiopathogenesis of DM1, or possibly they result simply secondarily to direct exposition to gluten.

A few published reports indicate that gluten might influence autoimmunologic response against pancreatic $\beta$ cells. For instance, Funda et al.(14) have observed that after treatment with a gluten-free diet, BB-line rats eliminated antibodies characteristic for diabetes. Conversely, Hummel et al.(15) did not observe either alterations of the levels of auto-antibodies or decrease in the risk of diabetes development after introduction of a gluten-free diet in the relatives of the DM1 patients. Inconsistent results of the aforementioned studies suggest that the relationship between DM1 and celiac disease is of complex character.

Gluten found in everyday diet appears to be a modulator and not a determining factor in DM1 ethiopathogenesis. It allows other factors, which in patients with genetic predisposition to DM1 development might activate autoimmune response against pancreatic $\beta$ cells to have better access to lamina propria of the intestinal mucosa (16).

Authors of a few published studies suggest that immunologic processes responsible for destruction of pancreatic $\beta$ cells at an early stage of DM1 development persist during the chronic stage of the disease and might influence the development of late complications, including diabetic nephropathy and retinopathy (17-19). Our results have confirmed increased activity of TNF- $\alpha$ and IL- 6 and decreased activity of IL-10 in DM1 patients, especially among children who had the course of disease complicated by occurrence of pathologic events in the kidneys and eye apparatus (7).

Observed elevated serum levels of TNF- $\alpha$ and IL-6 and decreased level of IL-10 in DM1 children with coexistent celiac disease when compared with the patients without confirmed celiac disease suggest that these cytokines play a significant role in celiac disease development among DM1 children. Elevated levels of proinflammatory cytokines observed in the course of DM1 might account not only for damage to kidneys and eye apparatus but also for impairment of intestinal mucosa.

Statistically significant correlation between TNF- $\alpha$ and IgA-anti-tTG, as shown in our work, might suggest that TNF- $\alpha$ is among major factors responsible for damage to the small intestine epithelium and increase in tTG secretion (20). Recently, a few studies were published on the role of antibodies against tTG (anti-tTG) in celiac disease diagnosis (21). Our studies provide further evidence that IgA-anti-tTG antibodies, among the other so far analyzed antibodies, may become the most sensitive screening indicator of latent celiac disease in DM1 children.

The enzyme, by means of deaminase mechanism, modifies the structure of gliadin, which consequently becomes more immunogenic (21). Moreover, TNF- $\alpha$ working together with IL-6 increases expression of HLA-DQ genes in the intestinal epithelium allowing for more gliadin to be presented to the intestinal mucosa's T lymphocytes (22).

Some authors claim that early detection of celiac disease in DM1 children is of considerable clinical significance. The introduction of gluten-free diet in patients with coexistent DM1 and celiac disease might allow patients in future to reach adequate height, to achieve puberty, and to have better metabolic compliance of DM1 (23). It might also prevent diabetic microangiopathy development (24). However, some published reports show no observable effect of better metabolic compliance of DM1 while on a gluten-free diet (25). In such studies, the occurrence of celiac disease in DM1 children appears to be only partially triggered by direct exposure to gluten. This begs 
the question: how much does poor metabolic control of DM1 influence the prevalence of celiac disease in those patients? The results of our studies show significantly higher HbA1c levels and significantly increased $24 \mathrm{~h}$ urinary albumin secretion in children with DM1 and concomitant celiac disease in relation to diabetic patients without coexistent celiac disease.

Our study has shown statistically significant positive correlation between serum TGA and HbA1c levels. These results suggest that poorer metabolic compliance of DM1 is related to higher risk of celiac disease development in DM1 children. In the course of DM1, hyperglycemia plays a crucial role in initiation and progression of tissue damage by nonenzymatic glycation (26). Glycated proteins when binding to their specific receptors located on the cell membrane of the macrophages trigger release of TNF- $\alpha$, IL-6, IL-12, and IL-2 cytokines $(26,27)$. These multifunctional cytokines may modulate inflammatory response in the intestinal mucosa and thus take part in its impairment and celiac disease development in DM1 children (28).

Increasing number of evidence suggest that the starting point for the development of the inflammatory reaction in the intestinal mucosa is not only the increase in TNF- $\alpha$ and IL-6 production but also inadequate low production of the antiinflammatory cytokines aimed at reduction of the neurotoxic effect of the proinflammatory cytokines $(27,29)$. Animal models show that depletion of regulatory $\mathrm{TCD} 4{ }^{+} \mathrm{CD} 25^{+}$lymphocytes producing IL-10 in mice causes spontaneous development of enterocolitis (30). However, improvement in the medical condition of chronic enterocolitis was observed after administration of the exogenous IL-10 $(31,32)$. Such a therapy blocked excessive secretion of TNF- $\alpha$ and INF $\gamma$ (33). In the available literature, no work that focused on the assessment of IL-10 levels in children with DM1 and concomitant celiac disease was found. Our previously published studies have shown that there is a shortage of IL-10 in children with DM1, especially among children who had the course of disease complicated by the occurrence of pathologic events in the kidneys and the eye apparatus (7). In the current study of 19 children with DM1 and diagnosed with concomitant celiac disease, as many as $14(74 \%)$ children did not present any activity of this cytokine in the blood serum. Preliminary analysis of the IL-10 level in the group of examined children with DM1 and celiac disease suggests that higher secretary activity of IL-10 might have a protective effect thus preventing celiac disease development. Introducing IL-10 to the antiinflammatory therapeutic protocols of other disorders of the digestive tract, including colitis ulcerosa, was a therapeutic success $(34,35)$. Further research to assess the negative influence of IL-10 depletion on celiac disease development in children with DM1 may allow for future introduction of similar therapies to increase the IL-10 level in this particular group of patients.

In addition, the results of our research on the role played by TNF- $\alpha$ encourage efforts aimed at early introduction of immunologic treatment to inhibit TNF- $\alpha$ activity. In recent years, several studies were published on the role of TNF- $\alpha$ in promoting inflammatory processes in the course of chronic intestinal diseases (36). Numerous pharmacologic protocols to inhibit TNF- $\alpha$ activity (including infliximab, CDP571, and $\mathrm{MAb}$ ) are currently carried out worldwide (37-40).

From our data, TNF- $\alpha$ appears to be an essential factor of celiac disease development. Possibly, early introduction of TNF- $\alpha$ antagonists to the treatment of DM1 patients in whom elevated levels of this cytokine were detected might prevent celiac disease development and late diabetic complications. In addition, in patients already diagnosed with celiac disease, especially if few effects of the gluten-free diet are observed, it might help to obtain metabolic compliance of the diabetes.

\section{REFERENCES}

1. Ventura A, Magazzu G, Greco L 1999 Duration of exposure to gluten and risk for autoimmune disorders in patients with celiac disease. SIGEP Study Group for Autoimmune Disorders in Celiac Disease. Gastroenterology 117:297-303

2. Not T 2001 Undiagnosed celiac disease and risk of autoimmune disorders in subjects with type 1 diabetes. Diabetologia 44:151-155

3. Myśliwiec M, Balcerska A, Stępiński J, Bąkowska A, Jędrzejczyk A 2006 [Prog nostic factors of celiac disease occurrence in type 1 diabetes mellitus children]. Endokrynol Diabetol Chor Przemiany Materii Wieku Rozw 12:281-285

4. Farrell RJ, Kelly CP 2002 Celiac sprue. N Engl J Med 346:180-188

5. Sumnik Z 2000 HLA-DQA1*05-DQB1*0201 positivity predisposes to celiac disease in Czech diabetic children. Acta Paediatr 89:1426-1430

6. Hanifi-Moghaddam P, Schloot NC, Kappler S, Seissler J, Kolb H 2003 An association of autoantibody status and serum cytokine levels in type 1 diabetes. Diabetes 52:1137-1142

7. Myśliwiec M, Zorena K, Balcerska A, Mysliwska J, Lipowski P, Raczyńska K 2006 The activity of $N$-acetyl-beta-D-glucosaminidase and tumor necrosis factor-alpha at early stage of diabetic retinopathy development in type 1 diabetes mellitus children. Clin Biochem 39:851-856

8. Myśliwiec M, Balcerska A, Zorena K, Myśliwska J, Lipowski P, Raczyńska K 2008 The role of vascular endothelial growth factor, tumor necrosis factor alpha and interleukin-6 in pathogenesis of diabetic retinopathy. Diabetes Res Clin Pract 79:141-146

9. Myśliwiec M, Balcerska A, Zorena K, Myśliwska J 2006 Serum and urinary cytokine homeostasis and renal tubular function in type 1 diabetes mellitus children. J Pediatr Endocrinol Metab 19:1421-1427

10. Zorena K, Myśliwska J, Myśliwiec M, Balcerska A, Lipowski P, Raczyńska K 2008 Interleukin 12 and tumor necrosis factor- $\alpha$ equilibrium is prerequisite for clinical course free from late complications in type 1 diabetes mellitus children. Scand J Immunol 67:204-208

11. American Diabetes Association 2003 Diagnosis and classification of diabetes. Diabetes Care 26:3160-3167

12. Oberhuber G, Granditsch G, Vogelsang H 1999 The histopathology of coeliac disease: time for a standardized report scheme for pathologists. Eur J Gastroenterol Hepatol 11:1185-1194

13. Ladinser B, Rossipal E, Pittschieler K 1994 Endomysium antibodies in coeliac disease: an improved method. Gut 35:776-778

14. Funda DP, Kaas A, Bock T, Tlaskalová-Hogenová H, Buschard K 1999 Gluten-free diet prevents diabetes in NOD mice. Diabetes Metab Res Rev 15:323-327

15. Hummel M, Bonifacio E, Naserke HE, Ziegler AG 2002 Elimination of dietary gluten does not reduce titers of type 1 diabetes-associated autoantibodies in high-risk subjects. Diabetes Care 25:1111-1116

16. Kostraba JN 1994 What can epidemiology tell us about the role of infant diet in the etiology of IDDM? Diabetes Care 17:87-91

17. Schram MT, Chaturvedi N, Schalkwijk C, Giorgino F, Ebeling P, Fuller JH, Stehouwer CD 2005 EURODIAB Prospective Complications Study Group: markers of inflamantion are cross-sectionally associated with microvascular complications and cardiovascular disease in type 1 diabetes. The EURODIAB Prospective Complications Study. Diabetologia 48:370-378

18. Targher G, Zenari L, Bertolini L, Muggeo M, Zoppini G 2001 Elevated levels of interleukin-6 in young adults with type 1 diabetes without clinical evidence of microvascular and macrovascular complications. Diabetes Care 24:956-957

19. Myśliwiec M, Balcerska A, Zorena K, Myśliwska J, Nowacka M, Lipowski P, Raczyńska K 2006 [Selected immunologic and biochemical risk factor of the retinopathy and nephropathy development in children with diabetes mellitus type 1]. Endokrynol Diabetol Chor Przemiany Materii Wieku Rozw 12:269-273

20. Fabris M, Visentini D, De Re V, Picierno A, Maieron R, Cannizzaro R, Villalta D, Curcio F, De Vita S, Tonutti E 2007 Elevated B cell-activating factor of the tumor necrosis factor family in celiac disease. Scand J Gastroenterol 42:1434-1439

21. Sakly W, Bienvenu F, Peretti N, Lachaux A, Morel S, Bouvier R, Nicolino M, Bienvenu J, Spiteri A, Fabien N 2005 IgA antitransglutaminase antibodies as a tool for screening atypical forms of coeliac disease in a French at-risk paediatric population. Eur J Gastroenterol Hepatol 17:235-239

22. Garrote JA, Arranz E, Górnez-González E, Leon AJ, Farre C, Calvo C, Bernardo D, Fernández-Salazar Ł, Blanco-Quirós A 2005 IL 6, IL-10 and TGFB1 gene polymorphisms in coeliac disease: differences between DQ2 positive and negative patients. Allergol Immunopathol (Madr) 33:245-249 
23. Amin R, Murphy N, Edge J, Ahmed ML, Acerini CL, Dunger DB 2002 A longitudinal study of the effect of a gluten-free diet on glycemic control and weight gain in subjects with type 1 diabetes and celiac disease. Diabetes Care 25:1117-1122

24. Glastras SJ, Craig ME, Verge CF, Chan AK, Cusumano JM, Donaghue KC 2005 The role of autoimmunity at diagnosis of type 1 diabetesin in the development of thyroid and celiac disease and microvascular complications. Diabetes Care 28:21702175

25. Kaukinen K, Salmi J, Lahtela J, Siljamäki-Ojansuu U, Koivisto AM, Oksa H, Collin P 1999 No effect of gluten-free diet on the metabolic control of type 1 diabetes in patients with diabetes and celiac disease. Retrospective and controlled prospective survey. Diabetes Care 22:1747-1748

26. Morohoshi M, Fujisawa K, Uchimura I, Numano F 1995 The effect of glucose and advanced glycosylation end products on IL-6 production by human monocytem. Ann NY Acad Sci 748:562-570

27. Hansson T, Danneus A, Klareskog L 1999 Cytokine-producing cells in periphera blood of children with coeliac disease secrete cytokines with a type 1 profile. Clin Exp Immunol 116:246-250

28. Przemiosło RT, Kontakou M, Nobili V, Ciclitira PJ 1994 Raised pro-inflammatory cytokinez interleukin 6 and tumour necrosis factor $\alpha$ in celiac disease mucosa detected by immunohistochemistry. Gut 35:1398-1403

29. Salvati VM, Mazzarella G, Gianfrani C, Levings MK, Stefanile R 2005 Recombinant human interleukin 10 suppresses gliadin dependent $\mathrm{T}$ cell activation in ex vivo cultured coeliac intestinal mucosa. Gut 54:46-53

30. Sellon RK, Tonkonogy S, Schultz M 1998 Resident enteric bacteria are necessary for development of spontaneous colitis and immune system activation in interleukin-10 deficient mice. Infect Immun 66:5224-5231

31. Herfarth H, Scholmerich J 2002 IL-10 therapy in Crohn's disease: at the crossroads. Gut 50:146-147
32. Sandborn WJ, Targan SR 2002 Biologic therapy of inflammatory bowel disease Gastroenterology 122:1592-1608

33. Rizzo LV, XU H, Chan CC, Wiggert B, Caspi RR 1998 IL-10 has a protective role in experimental autoimmune uveoretinitis. Int Immunol 10:807-814

34. Lugering N, Kucharzik T, Stein H 1998 IL-10 synergizes with IL-4 and IL-13 in inhibiting lysosomal enzyme secretion by human monocytes and lamina propria mononuclear cells from patients with inflammatory bowel disease. Dig Dis Sci 43:706-714

35. Fedorak RN, Gangl A, Elson CO, Rutgeerts P, Schreiber S, Wild G, Hanauer SB, Kilian A, Cohard M, LeBeaut A, Feagan B 2000 Recombinant human interleukin 10 in the treatment of patients with mild to moderately active Crohn's disease. The Interleukin 10 inflammatory Bowel Disease Cooperative Study Group. Gastroenterology 119:1473-1482

36. Raddatz D, Bockemúhl M, Ramadori G 2005 Quantitative measurement of cytokine mRNA in inflammatory bowel disease:relation to clinical and endoscopic activity and outcome. Eur J Gastroenterol Hepatol 17:547-557

37. Tilg H, Feichtenschlager T, Knoflach P, Petritsch W, Schőfl R, Vogelsang H, Reinisch W 2007 [Use of infliximab in ulcerative colitis]. Z Gastroenterol 45:907911

38. Wewer V, Riis S, Vind I 2006 Infliximab dependency in a national cohort of children with Crohn's disease. J Pediatr Gastroenterol Nutr 42:40-45

39. Colombel JF, Loftus EV Jr, Tremaine WJ, Egan LJ, Harmsen WS, Schleck CD, Zinsmeister AR, Sandborn WJ 2004 The safety profile of infliximab in patients with Crohn's disease: the Mayo clinic experience in 500 patients. Gastroenterology 126:19-31

40. Feagan BG, Sandbom WJ, Lichtenstein G, Radford-Smith G, Patel J, Innes A 2006 CDP571, a humanized monoclonal antibody to tumour necrosis factor-alpha, for steroid-dependent Crohn's disease: a randomized, double-blind, placebo-controlled trial. Aliment Pharmacol Ther 23:617-628 